Resonance Absorption in Nuclear Reactors

By Lawrence Dresner. (International Series of Monographs on Nuclear Energy. Division 10 : Reactor Design Physics, Vol. 4.) Pp. $x+131$. (London and New York: Pergamon Press, 1960.) 40s. net. $\mathrm{N}$ important problem in the physics of nuclear A reactor design is to predict the proportion of the nuclear resonances of uranium-238 and other elements. During recent years the accumulation of basic experimental data on resonances has enabled. reactor physicists to attempt to calculate the absorption directly from neutron transport theory, as an alternative to the customary use of empirical methods.

The present monograph gives a timely account of modern theoretical work in the field, as well as a critical comparison of theory with experiment. It is primarily intended for those well versed in reactor physics, and contains little on the more descriptive type of theoretical treatment developed by the early workers.

There are two introductory chapters giving a brief historical survey and an account of the general transport theory of neutron slowing-down in absorbing media. The greater part of the book is devoted to the development of approximate methods to deal specifically with resonance absorption in homogeneous and heterogeneous systems. Various special topies are discussed, for example, the interaction between neighbouring absorbers, and the Doppler broadening of resonances due to rise in temperature. The only significant omission noted is an explanation of the empirical formulo used for representing the experimental results. A critical discussion of these formulæ in the light of the preceding theoretical chapters would have been desirable.

A valuable feature of the book is the orderly presentation of key results from many published papers and official reports. It can be warmly recommended.

J. CODD

Plant Physiology

A Treatise. Edited by F. C. Steward. Vol. IB Photosynthesis and Chemosynthesis. Pp. xvii +348. (Now York: Academic Press, Inc.; London: Academic Press, Inc. (London), Ltd., 1960.) 12 dollars.

THIS volume contains two articles, a longer one extending to 242 pages of text by $H$. Gaffron. on the mechanism of photosynthesis, and a shorter one of 37 pages by M. Gibbs and J. A. Schiff on the energy relations of chemo-autotrophic bacteria. Both articles are followed by an adequate list of references.

The work of Van Niel in 1931 on photosynthetic bacteria, the discovery of the chloroplast or Hill reaction some eight years later, and subsequent work with radioactive isotopes, aimed at discovering the fate of the carbon in the carbon dioxide absorbed in photosynthesis, led to views on the mechanism of photosynthesis, which are now generally, though not universally, supposed to involve the photolysis of water and the incorporation of the absorbed carbon into a phosphorylated pentose, giving a substance from each molecule of which two molecules of a phosphorylated triose, phosphoglyceric acid, are produced. In the present volume Gaffron gives a detailed account of all the processes and reactions involved in photosynthesis as suggested by recent researches and of the findings on which present-day views are based. The mechanism of photosynthesis is obviously a very complex one, and the botanist who comes to read this account without some acquaintance with the present position of the subject may find some of it, particularly the part dealing with photochemical considerations, rather difficult reading. The arguments for the views adopted are put forward very fairly.

The small article on the energy relations of chemo. autotrophic organisms brings together what is known concerning chemosynthesis in nitrifying, nitrating and non-photosynthetic sulphur bacteria, and will be found useful by those requiring information on this topic.

W. Stiles

\section{Birds of the West Indies}

By James Bond. Pp. $256+8$ plates. (London: William Collins, Sons and Co., Ltd., 1960.) 35s. net. THIS is a field guide to 429 species of which 266 are illustrated, 80 being in colour. There are short descriptions of the main features of each family, which will be a help to the novice in the absence of keys. The text of each species consists of the usual descriptive material, including local names, a useful addition in a region where several languages are in use. Mercifully there are no sub-species.

Colour figures are mainly good; the line drawings have rather too much detail for the size reduction and are inclined to be fuzzy, though this may be partly the fault of the paper used, for the letters of the text also are sometimes lacking in sharpness.

James Bond has been associated with ornithology in the West Indies for half a lifetime, and his know. ledge of the birds of that region is unequalled. This illustrated guide will be a great boon to professional and amateur, even traveller and visitor with the most casual interest in birds.

\section{Servomechanisms}

An Introduction to the Practice and Theory of ClosedLoop Position-Control Systems, with an Account of Methods of Data Transmission and Computation. By P. L. Taylor. (Electrical Engineering Series.) Pp. xiv +418. (London : Longmans Green and Co., Ltd., 1960.) 42s. net.

N. P. L. TAYLOR, who has had considerable V experience in teaching the theory of control systems to students of aeronautical and other branches of engineering, has written this introductory text-book for use in technical colleges and universities. It has refreshing elements of novelty in substance and arrangement. Within its intentionally Jimited scope, it is well adapted to the needs of both students and lectures.

The analysis is developed in a simple manner using, in the first half of the book, no more mathematies than simple linear differential equations. An account of such physical elements as are involved in measurement, data transmission, operation and analogue computation is given in the second chapter.

The second half of the 400 pages develops the theory of linear continuous systems, proceeding via an excellent summary of the essential properties of the complex variable to the Laplace transform, leaving the response to sinusoidally varying input quantities to be developed by an application of the Laplace transform. This sequence is not the usual one, partly because the teaching of the analysis of linear systems with sinusoidal inputs can usually presume familiarity with the techniques of electrical 